Emerald Journal of Forensic Practice

\title{
Work related stress in forensic mental health professionals: A systematic review
}

\begin{tabular}{|r|l|}
\hline Journal: & Journal of Forensic Practice \\
\hline Manuscript ID & JFP-05-2016-0024.R4 \\
\hline Manuscript Type: & Research Paper \\
\hline Keywords: & Stress, Burnout, Forensic, Mental Health Professionals, Staff, Interventions \\
\hline \multicolumn{2}{|l}{} \\
\hline
\end{tabular}

SCHOLARONE $^{\text {Ix }}$

Manuscripts 


\section{Work related stress in forensic mental health professionals:}

A systematic review

\section{Purpose}

The purpose of this paper is to investigate the prevalence of stress and burnout among forensic mental health professionals (FMH).

\section{Design/methodology/approach}

A systematic review of the available literature accessed by relevant databases was conducted.

Findings

This study concluded that FMH suffer from moderate levels of both stress and burnout. There is insufficient evidence to establish that they suffer from higher levels of stress than their non-forensic colleagues. Interventions such as PSI (psychosocial intervention) training have been reported to demonstrate an improvement in staff knowledge and attitudes toward patients, whilst reducing burnout.

\section{Practical implications}

Stress in $\mathrm{FMH}$ is a cause of concern. Conclusions drawn are applicable only to nursing staff as other professions were not adequately represented. As most studies used the burnout scores, results were directly comparable. Further 
research is needed to fully evaluate stress and burnout in professionals who work within forensic mental health settings.

\section{Originality/Value}

High levels of stress and burnout have negative effects on an individual's ability to work and subsequently there is a financial and also moral incentive for the management of health service workforces to intervene. This study highlights that $\mathrm{FMH}$, as a population, are at risk.

\section{Keywords}

Stress, burnout, forensic, mental health professionals, staff, interventions

\section{Background}

Occupational stress is defined as psychological strain due to individual and workplace stressors (Finney et al, 2013). Burnout is the consequence of chronic occupational stress and is described as a 'state of physical, emotional and mental exhaustion,' (Pines et al, 1981 and Freudenberger, 1974). It is characterised by feelings of detachment, cynicism, low self-esteem and a decreased sense of personal accomplishment (Maslach et al, 1996). Those 
working in an occupation where interpersonal relationships are crucial are prone to higher levels of burnout (Maslach et al, 1996). Nursing and other healthcare professions have been identified as being particularly at risk (Cacciacarne et al., 1986). The consequences are clear, as healthcare professionals have higher levels of physical and psychological ill health and greater sickness absence in comparison with the rest of the United Kingdom working population (Wall et al., 1997; Williams et al., 1998). A study involving 1,800 nurses found $93 \%$ had experienced varying degrees of work related stress (Cole, 1992). It has been suggested that $25 \%$ of all nurses suffer from symptoms of burnout (Landau, 1992). In addition, stress has been identified as one of the major reasons why nurses fail to achieve an optimum level of effectiveness at work (Kendrick, 2000; Joseph, 1993).

In comparison to healthcare staff in other specialities, mental health professionals are at particularly high risk of developing stress and burnout; a pattern confirmed in several reviews (Edwards et al., 2000; Paris \& Hoge, 2010; Rossler, 2012). This may be a contributing factor to the high staff turnover rates within the mental healthcare sector (Ben-Dror, 1994). A recent literature review (Morse et al, 2012) highlights the significant problem that burnout poses to the overall mental health workforce and exposes a lack of basic research in this area.

Another important risk factor is the perceived or actual threat of violence (Larkin et al., 1988). Forensic professionals are more likely to be subject to verbal or 
physical aggression therefore significantly increasing their risk of developing stress and suffering burnout (Mason, 2002).

Literature on stress amongst forensic professionals is sparse and there are no systematic reviews of literature concerning work related stress and burnout amongst multi-disciplinary professionals caring for forensic patients. A selective review investigating stress among forensic mental health nurses concluded there was sufficient evidence of stress among staff (Dickinson \& Wright, 2008). However, the level of stress they experienced was similar but not higher than that experienced by non-forensic colleagues. The findings were surprising considering the intense nature of their working environment.

Given the noticeable lack of literature, a systematic review of the literature on prevalence of stress and burnout amongst forensic mental healthcare professionals was conducted.

\section{Method}

The authors conducted a systematic review of papers that measured the prevalence and indicators of both stress and burnout among forensic mental health professionals. The Cochrane Collaboration systematic review methodology was used as outlined in the Cochrane Handbook for systematic reviews of interventions (Higgins \& Green, 2009). 


\section{Search strategy}

The literature search was developed via electronic databases through Health Information for London Online (library network). Databases searched included PsycINFO, Medline and Embase. On reflection CINAHL was later searched using the same strategy to identify relevant articles. For full details see Figure 1.

\section{Study selection}

The sample was limited to mental health professionals working directly with offenders or inpatients currently detained due to their risk of violent or threatening behaviour. Professionals were hospital or community based. Professionals included in the study were predominantly nursing staff, but other occupations were included such as carers, psychiatrists and occupational therapists. Studies involving prison staff, forensic scientists, mortuary workers and sexual assault nurse examiners (SANE) were excluded as their work is not based on the mental healthcare of patients.

In recent years forensic psychiatry has benefiting from developments in medicolegal understanding, the evolution of legal tests to define legal insanity, change in public attitude, service delivery changes and new treatments of mental conditions, offering an alternative to custodial sentencing (Arboledez-Florez, 2006). To ensure relevance to current clinical practice only papers from the turn of the century until the search date (2000 - January, 2015) were included in this review. Only papers written in English language were included. 


\section{Assessment of bias risk}

Studies were assessed for bias according to the Cochrane Handbook (Higgins \& Green, 2009). Each study was examined for selective reporting and to ensure use of randomisation and blinding.

\section{Statistical analysis}

When appropriate, meta-analysis of results was considered if studies utilised the same outcome assessment tool.

[Please insert Figure 1]

\section{Results}

Seventeen studies were found and details listed in Table1.

Description of studies

\section{Settings}

Two studies were conducted in a low security forensic setting, eight in medium and three in a high secure setting. Fourteen of the seventeen studies were carried out in an inpatient setting compared to one study in an outpatient setting. The remaining two studies (Happell et al., 2003a; Happell et al., 2003b) examined staff from various settings. Thirteen of the studies were based in the 
U.K. with the remaining four from Canada, Australia and Norway. Four studies were multi-site.

\section{Sample population}

All studies assessed stress or burnout among forensic mental health nurses. One study (Chalder \& Nolan, 2000) reported a population that included nine occupational therapists; however they were not available to follow-up and were not included in final numbers. No studies assessed stress among doctors, psychiatrists or psychologists.

\section{Sample size and response rate}

Most studies were small and had limited sample size. Seven studies had a sample size of less than 50 and only six of the studies had a sample size of more than 100 participants. The average sample size was 109 participants (range from 12 to 636 ). Response rate for nine of the studies was below $60 \%$.

\section{Validated measures of outcome}

All seventeen studies used a validated outcome measure and in many, the Maslach Burnout Index (MBI) was used. The $\mathrm{MBI}$ is a 22-item questionnaire assessing burnout on three subscales: emotional exhaustion, depersonalization and personal accomplishment (Maslach et al., 1996). High mean scores on the emotional exhaustion and depersonalisation subscales indicate high levels of burnout. Conversely a low score on the personal accomplishment subscale demonstrates a tendency to view oneself as incompetent, particularly at work, 
therefore indicating a high level of burnout. The scores of the subscales are not cumulative; for each subscale the respondents can be identified as suffering from low, moderate or high burnout. Thirteen of the seventeen studies were able to provide data of MBI scores (Table 1).

Several studies investigated other relevant outcomes such as job satisfaction, the effect of violence, post-traumatic stress symptoms and the positive effect of further staff training. Additional conclusions have been drawn with those results in mind despite not being the focus of the review.

(Please insert Table 1)

$\underline{\text { Assessment of bias risk }}$

The quality of reporting varied. Only two of the five studies investigating the effect of interventions used randomisation for the allocation of participants to groups (Ewers et al., 2002; Redhead et al., 2011). The remaining studies did not comment and therefore it is assumed that this was not carried out. None of the studies specified that blinding was used. Given that many of the studies used postal questionnaires or were conducted among small study samples it is likely that blinding would not have been feasible.

Outcome measures used to assess stress were self-reported and therefore subjective. This greatly increases the effect any bias has on the reliability of the results, but is arguably unavoidable in psychological healthcare. 
The studies were examined for examples of selective reporting. Two studies (Blumenthal et al., 2011; Decaire et al., 2006) were found to neglect reporting raw data on outcome measures, including $\mathrm{MBI}$ scores. This generates some uncertainty about potential reporting bias and a lack of methodological transparency.

\section{Outcome of results}

Overall, considering personal accomplishment, three of the studies found that forensic mental health staff had low scores in this area, indicating a high level of burnout. Eight studies demonstrated moderate burnout levels. With regards to emotional exhaustion, seven studies indicated moderate levels and three low levels of burnout, whilst for the subscale of depersonalisation six studies indicated moderate and five, low levels of burnout. The remaining studies did not draw any conclusion. In instances where interventions changed outcome results, the stress / burnout measures were assessed in the control group.

\section{Effect of intervention}

Six of the seventeen studies investigated interventions to lower stress and burnout among staff.

Two studies investigated psychosocial intervention training (PSI). PSI training is a practical course designed to provide staff with the skills needed to reduce distress and improve the functioning of people suffering from schizophrenia. The course encourages staff to challenge their beliefs about psychotic illness 
with the aim to improve their own understanding and foster empathy (Ewers, 2002).

Three studies examined other psychological therapies and the remaining study considered the effect of introducing single sex inpatient wards. None of the studies had adequate follow-up to determine the longevity of the effects. Control groups were either parallel staff samples who received 'treatment as usual,' or were the same staff members at baseline.

(Please insert Table 2)

$\underline{\text { Statistical analysis }}$

Due to their clinical and methodological diversity, the group of studies reporting results using $\mathrm{MBI}$ was considered as heterogeneous; therefore meta-analysis was not possible.

\section{Discussion}

We investigated the prevalence of stress and burnout amongst forensic mental health professionals and have reported the results of 17 studies. Overall, studies reported moderate levels of stress. Some studies asked directly about the participant's experience of stress whilst others drew conclusions from indicators such as post-traumatic stress symptoms, job satisfaction etc. Burnout was assessed through three sub-measures: emotional exhaustion, depersonalisation and personal accomplishment. Sub-measure scores were collated and largely signified moderate levels of burnout. 


\section{Effect of interventions}

The small number of studies which investigated the effect of various interventions demonstrated mixed, but mainly positive results. PSI training improved staff knowledge and attitudes whilst significantly reducing aspects of burnout (Ewers et al., 2002; Redhead et al., 2011). A recent systematic review concluded similar findings (Stewart et al, 2014). Similarly, the introduction of a three month programme of multi-disciplinary therapy reduced staff burnout (Long et al., 2008). Interestingly, one paper found that a change from mixed to single sex wards significantly increased levels of burnout, especially among staff working on the female inpatient ward (Nathan et al., 2007). This is an interesting finding since the healthcare system in the UK has moved from mixed to single sex wards. Other interventions, such as challenging behaviour workshops and team reflective practice did not significantly reduce stress or burnout (Berry et al., 2012; Blumenthal et al., 2011).

\section{Comparison to other groups}

Howard (2009) found that staff working in a forensic unit had slightly higher levels of emotional exhaustion than those who worked in the community. Despite this they appeared to have greater levels of personal achievement and had a significantly lower fear of violence. Chalder and Nolan (2002) found there was no difference in the levels of stress experienced by acute general and forensic mental health nurses. Surprisingly, the study by Happell (2003a) found 
that forensic staff had significantly less burnout and had greater job satisfaction than non-forensic staff.

On balance the three studies do not support the theory that forensic staff suffer from higher levels of stress than non-forensic staff, surprising given the increased threat of violence. Chalder et al (2000), suggests that there is a degree of self-selection in forensic mental healthcare, in that it tends to attract strong, assertive personalities that are less prone to stress. They also propose that forensic units recognise the risk of violence and so provide adequate support.

\section{Study Population}

The aim of this study was to investigate levels of work related stress in a selection of professionals within the forensic mental health multidisciplinary team. The limited variety of professions included in this review clearly highlights the lack of research in this area.

The conclusions drawn from this review are only relevant to a nursing population as other professions were not well represented in this selection of studies. One exception was the inclusion of occupational therapists (OT) in the study by Oddie and Ousley (2007). Unfortunately none of the nine OT's invited to participate did so and hence the profession did not contribute to the results of the study. 


\section{Comparison to other literature}

Edwards and Burnard (2003) investigated stress among community general mental health nursing. They found various factors that were associated with higher levels of stress, including higher workload, time management issues and dealing with potentially violent or suicidal patients. In particular the association between stress and violence risk supports the hypothesis of this study.

Studies directly investigating forensic mental healthcare have found that staff do suffer from stress. However, studies that compare forensic and general staff have found that there is no obvious difference. This finding is in keeping with the conclusions drawn from this review. Dickinson and Wright (2008) speculated that the stress-inducing effect of the forensic setting is limited by positive factors such as clinical supervision, professional development and supportive management.

\section{Strengths}

All studies included used a validated tool to measure stress or burnout, in most cases the MBI. As thirteen of the seventeen studies used the MBI score, results were directly comparable.

\section{Limitations}

The main limitation is that many of the studies published were of poor eminence. Nine of the studies had response rates below $60 \%$. This factor along with limited sample sizes reduces the reliability of the results. It can be argued that 
those who perceive more stress are more likely to be respondents, therefore positively skewing the results. Factors outside work such as domestic experiences and relational problems can affect perceived occupational stress and are confounding variables. None of the studies measured these variables and this may have again positively skewed the results.

There is the potential that relevant literature may have been missed as our search strategy had a high dependence on electronic databases. However given our relatively recent search dates, the chances of this are small. Another limiting factor is that only studies published in English were included due to difficulties in access to translation services.

It became apparent that CINAHL (search database for nursing staff and allied health professionals) was not included in the original search for literature. This was identified as a significant limitation given that all of the included papers concerned the welfare of nursing staff and a CINAHL review was duly done (strategy as documented in Figure 1). Two papers (Reid, 2014; Curtis \&Day, 2013) were identified as being relevant but were excluded following examination of the inclusion criteria. Reid (2014) had a study sample of nurses who worked in a variety of settings, both forensic and non-forensic. No conclusions or raw data pertaining to forensic nurses alone was available and on that basis it was excluded. Curtis and Day (2013) had a small study sample of psychologists who had worked in prisons. The study did not clarify but it was evident from sample data that not all volunteers were currently employed in forensic positions. As our 
study looks at stress and burnout in relation to current employment it too, was excluded. Retrospective inclusion of either of these papers would not have affected the conclusions reached by this review. Neither of these studies used $\mathrm{MBI}$ to measure burnout.

\section{Further Research}

Future research should include large multi-site studies using well-validated outcome measures. These should include adequate follow-up if assessing the effect of interventions. They should also endeavour to control for factors outside work that may contribute to work-related stress. Replication of studies as well as expansion to include forensic mental health professionals other than nursing staff is required.

\section{Conclusions}

This review demonstrates that mental health staff working in a forensic setting experience moderate levels of both stress and burnout. There is not enough evidence to suggest that burnout is any higher than that described by staff working in other areas of mental healthcare. Interventions, in particular PSI training, display small but positive effects in reducing both stress and burnout. The lack of follow-up makes it difficult to ascertain the longevity of these positive effects. Conclusions drawn are applicable only to nursing staff as other professions were not adequately represented among the study sample. Future 
research involving larger, multi-disciplinary samples is needed to accurately assess stress and burnout in forensic mental healthcare professionals.

\section{Practical implications}

- Staff working with forensic mental health patients are at risk of developing stress while at work.

- High levels of stress and burnout have negative effects on an individual's ability to work and subsequently there is a financial and also moral incentive for the management of health service workforces to intervene.

- Interventions, in particular PSI-training appear to demonstrate small but positive effects in reducing stress and burnout. 


\section{References}

Arboleda-Florez, J. (2006). Forensic psychiatry: contemporary scope, challenges and controversies. World Psychiatry, 5(2), 87-91.

Ben-Dror, R. (1994), Employee turnover in community mental health organization: A developmental stages study. Community Mental Health Journal, 30(3), 243-257.

Berry. K., Barrowclough, C., Innes, C., Fitzgerald, M., Hartley, S. \& Haddock, G. (2012). A description and evaluation of a challenging behaviour workshop. Journal of Mental Health, 21(5), 478-484.

Blumenthal, S., Ruszczynski, S., Richards, R. \& Brown, M. (2011). Evaluation of the impact of a consultation in a secure setting. Criminal Behaviour and Mental Health, 21(4), 233-244.

Cacciacarne, M., Resnick, P.J., McArthur, C. \& Althof, S.E. (1986). Burnout in forensic psychiatric staff. Medicine and Law, 5(4), 303.

Chalder, G. \& Nolan, P. (2000). A comparative study of stress among forensic and acute mental health nurses. British Journal of Forensic Practice, 2(3), 24-29.

Coffey, M. (1999). Stress and burnout in forensic community mental health nurses: an investigation of its causes and effects. Journal of Psychiatric and Mental Health Nursing, 6(6), 433-443.

Coffey, M. \& Coleman, M. (2001). The relationship between support and stress in forensic community mental health nursing. Journal of Advanced Nursing, 34(3), 397-407.

Cole, A. (1992). Stress. High anxiety. Nursing Times, 88(12), 26-30. 
Curtis, A. \& Day, A. (2013). The impact of specialist training on professional identity, organisational membership, organisational commitment, and stress in correctional psychologists. The Journal of Forensic Practice, 15(2), 130-140.

Decaire, M.W., Bédard, M., Riendeau, J. \& Forrest, R. (2006). Incidents in a psychiatric forensic setting: association with patient and staff characteristics. Canadian Journal of Nursing Research, 38(3), 68-80.

Dennis, A.M., Leach, C. (2007) Expressed emotion and burnout: the experience of staff caring for men with learning disability and psychosis in a medium secure setting. Journal of Psychiatric and Mental Health Nursing, 14(3), 267-276.

Dickinson, T. \& Wright, K.M. (2008). Stress and burnout in forensic mental health nursing: a literature review. British Journal of Nursing, 17(2), 8287.

Edwards, D. \& Burnard, P. (2003). A systematic review of stress and stress management interventions for mental health nurses. Journal of Advanced Nursing, 42(2), 169-200.

Edwards, D., Burnard, P., Coyle, D., Fothergill, A. \& Hannigan, B. (2000). Stress and burnout in community mental health nursing: a review of the literature. Journal of Psychiatric and Mental Health Nursing, 7(1), 7-14.

Ewers, P., Bradshaw, T., McGovern, J. \& Ewers, B. (2002). Does training in psychosocial interventions reduce burnout rates in forensic nurses? Journal of Advanced Nursing, 37(5), 470-476. 
Finney, C., Stergiopoulos, E., Hensel, J., Bonato, S. \& Dewa, C.S. (2013). Organizational stressors associated with job stress and burnout in correctional officers: a systematic review. BMC Public Health, 13(1), 1.

Freudenberger, H.J. (1974). Staff burn-out. Journal of Social Issues, 30(1) 159165.

Happell, B., Martin, T. \& Pinikahana, J. (2003a). Burnout and job satisfaction: a comparative study of psychiatric nurses from forensic and a mainstream mental health service. International Journal of Mental Health Nursing, 12(1), 39-47.

Happell, B., Martin, T. \& Pinikahana, J. (2003b). Stress and burnout in forensic psychiatric nursing. Stress and Health, 19(2), 63-68.

Higgins, J.P.T. \& Green, S. (2009. Updated March 2011). Cochrane Handbook for Systematic Reviews of Interventions. Wiley-Blackwell Publishers: Chichester.

Howard, R., Rose, J. \& Levenson, V. (2009). The psychological impact of violence on staff working with adults with intellectual disabilities. Journal of Applied Research in Intellectual Disabilities, 22(6), 538-548.

Joseph, P. (1993). Occupational stress in psychiatric nursing. Journal of Advanced Nursing, 18(4), 591-601.

Kendrick, C.P. (2000). Comparing the effects of stress and relationship style on student and practicing nurse anaesthetists. American Association of Nurse Anaesthetists Journal, 68(2), 115-126.

Landau, K. (1992). Psycho-physical strain and the burn-out phenomenon amongst health care professionals. In M. Estryn-Behar, C. Gadbois \& M. 
Pottier (Eds). Ergonomie a l' hopital, International Symposium Paris. Editions Octares: Toulouse.

Langdon, P.E., Yágüez, L. \& Kuipers, E. (2007). Staff working with people who have intellectual disabilities within secure hospitals Expressed emotion and its relationship to burnout, stress and coping. Journal of Intellectual Disabilities, 11(4), 343-357.

Larkin, E., Murtagh, S. \& Jones, S. (1988). A preliminary study of violent incidents in a special hospital (Rampton). The British Journal of Psychiatry, 153(2), 226-231.

Lauvrud, C., Nonstad, K. \& Palmstierna, T. (2009). Occurrence of post traumatic stress symptoms and their relationship to professional quality of life (ProQoL) in nursing staff at a forensic psychiatric security unit: a cross-sectional study. Health and Quality of Life Outcomes, 7(1), 31.

Long. C., Collins, L., MacDonald, C., Johnston, D. \& Hardy, S. (2008). Staff stress and challenging behaviour on a medium secure development disabilities ward for women: the outcomes of organisational change, and clinical interventions. British Journal of Forensic Practice, 10(3), 411.

Maslach, C., Jackson, S.E. \& Leiter, M.P. (1996). Maslach Burnout Inventory Manual. ( $3^{\text {rd }}$ Ed.) Mountain View, Palo Alto, CA: Consulting Psychologists Press.

Mason, T. (2002). Forensic psychiatric nursing: a literature review and thematic analysis of role tensions. Journal of Psychiatric Mental Health Nursing, 9(5), 511-520. 
Morse, G., Salyers, M., Rollins, A., Monroe-DeVita, M. \& Pfhaler, C. (2012). Burnout in mental health services: A review of the problem and its remediation. Administration and Policy in Mental Health and Mental Health Services Research, 39(5), 341-352.

Nathan, R., Brown, A., Redhead, K., Holt, G., \& Hill, J. (2007). Staff responses to the therapeutic environment: a prospective study comparing burnout among nurses working on male and female wards in a medium secure unit. The Journal of Forensic Psychiatry and Psychology, 18(3), 342352.

Oddie, S. \& Ousley, L. (2007). Assessing burn-out and occupational stressors in a medium secure service. British Journal of Forensic Practice, 9(2), 3248.

Paris, M. \& Hoge, M.A. (2010). Burnout in the mental health workforce: a review. The Journal of Behavioral Health Services \& Research, 37, 519528.

Pines, A.M., Aronson, E. \& Kafry, D. (1981). Burnout: From tedium to growth. Free Press: New York.

Redhead, K., Bradshaw, T., Braynion, P. \& Doyle, M. (2011). An evaluation of the outcomes of psychosocial intervention training for qualified and unqualified nursing staff working in a low-secure mental health unit. Journal of Psychiatric and Mental Health Nursing, 18(1), 59-66.

Reid, M., (2014). Self-efficacy and job satisfaction in nurses who care for mentally disordered offenders: Matthew Reid analyses the relationship 
between these two complex concepts, and the possible implications this may have for practice. Mental Health Practice, 18(4), 29-36.

Reininghaus, U., Craig, T., Gournay, K., Hopkinson, P. \& Carson, J. (2007). The High Secure Psychiatric Hospitals' Nursing Staff Stress Survey 3: Identifying stress resistance resources in the stress process of physical assault. Personality and Individual Differences, 42(3), 397-408.

Rössler, W. (2012). Stress, burnout, and job dissatisfaction in mental health workers. European Archives of Psychiatry and Clinical Neuroscience, 262(2), 65-69.

Stewart, W. \& Terry, L. (2014). Reducing burnout in nurses and care workers in secure settings. Nursing Standard, 28(34), 37-45.

Wall, T.D., Bolden, R.I., Borrill, C.S., Carter, A.J., Golya, D.A., Hardy, G.E., Haynes, C.E., Rick, J.E., Shapiro, D.A. \& West, M.A. (1997). Minor psychiatric disorder in NHS trust staff: occupational and gender differences. The British Journal of Psychiatry, 171(6), 519-523.

Williams, S., Michie, S. \& Pattani, S. (1998). Improving the health of the NHS workforce. Report of the partnership on the health of the NHS workforce. Nuffield Trust, 1 September 1998. 
Screen by Abstract. Include those only related to objective, papers relevant to health care professionals. If unclear, paper included to next step of the search.

63

Following Search Terms:

1. 'Stress,' OR 'Burnout,' OR 'Job Satisfaction.'

2. 'Forensic,' OR 'Offender,' OR 'Secure.'

3. 'Staff,' OR 'nurse,' OR 'doctor,' OR 'psychiatrist,' OR 'psychologist,' OR 'physiotherapist,' OR 'care worker,' OR 'occupational therapist.'

4. 1. AND 2. AND 3.

Searches limited to English Language only, and dated from 2000 to January, 2015.

Search terms included in 'Title and Abstract.'
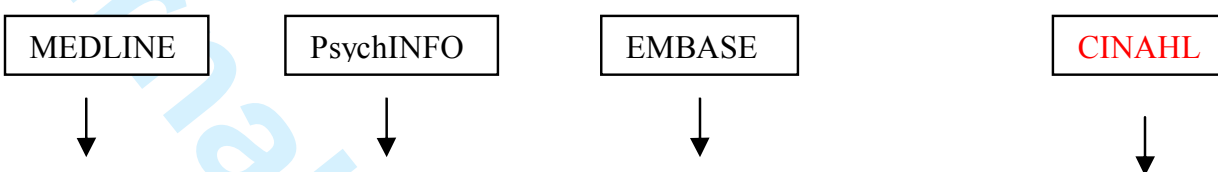

\begin{tabular}{|l|}
\hline 1.322974 \\
2.24867 \\
3.110362 \\
4.42 \\
\hline
\end{tabular}

\begin{tabular}{|l|}
\hline 1.83327 \\
2.18754 \\
3.53800 \\
4.71 \\
\hline
\end{tabular}

1. 369926

2. 33081

3. 142231

4. 68
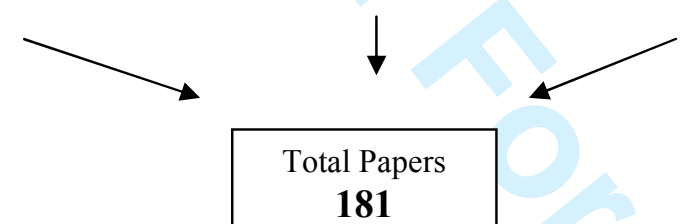

181
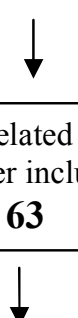

Remove Duplicates

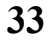

Screen by Full Text.

Inclusion Criteria

Must have validated tool to assess stress, burnout or job satisfaction.

Population sample of staff must have everyday contact with patients.

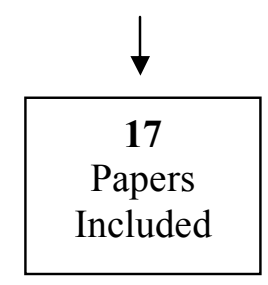

Screen by Full Text. Inclusion Criteria

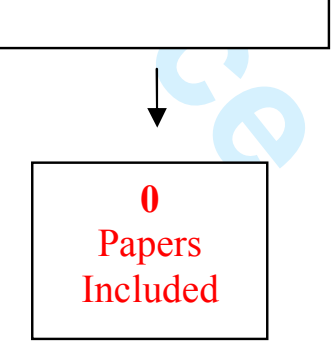




\begin{tabular}{|l|l|}
\hline Mean MBI Scores (In control group if a comparison trial) \\
\hline
\end{tabular}

(2011)

Chalder et al., (2000)

\begin{tabular}{l|l} 
Coffey and & A number of nurses reported burnout. Significant association between caseload and stress reported.
\end{tabular}

Coleman., (2001)

Decaire et al., (2006)

A small percentage of patients caused the majority of incidents. Lower frequency of incidents associated with staff experience and 'clarity' in work

environment. Higher frequencies associated with staff age, staff 'openness,' and staff who felt they had a greater sense of 'autonomy' in their work

environment. No correlation between staff burnout and patient incidents. No conclusions drawn with regard to stress level in staff.

\begin{tabular}{|lll} 
Dennis and Leach., & Almost a third of responses showed evidence of expressed emotion. No member staff fulfilled criteria for burnout. Suggested link between expressed
\end{tabular}

(2007) emotion and Dp.

After intervention, staff showed significant improvement in knowledge and attitudes. Significantly less evidence of burnout. Control group did not show any significant changes from baseline.

\begin{tabular}{l|l} 
Happell et al., & Significantly greater EE in mental health nurses compared to forensic mental health nurses. Significantly greater job satisfaction among forensic mental
\end{tabular} 2003a) $\quad$ health nurses.

\begin{tabular}{l|l} 
Happell et al., & 'Low' level of burnout, specifically moderate levels of EE and low levels of Dp and reduced PA.
\end{tabular}

(2003b)

Howard et al., Staff working in medium secure unit had a significantly lower fear of violence despite the fact they were at increased risk. Positive correlation between

\begin{tabular}{|c|c|c|}
\hline \multicolumn{3}{|c|}{ Mean MBI Scores (In control group if a comparison trial) } \\
\hline $\begin{array}{l}\text { Emotional } \\
\text { Exhaustion (EE) }\end{array}$ & $\begin{array}{l}\text { Depersonalization } \\
\text { (Dp) }\end{array}$ & $\begin{array}{l}\text { Personal } \\
\text { Accomplishment } \\
\text { (PA) }\end{array}$ \\
\hline $24.54 \ddagger$ & $7.54 \$$ & $36.38 \ddagger$ \\
\hline - & $7.1 \%$ & - \\
\hline- & - & - \\
\hline $20.74 \mathrm{M}+$ & & $32.45 \mathrm{M}+$ \\
\hline $17.76 \mathrm{~F}$ & $4.65 \mathrm{~F} \dagger$ & $33.62 \mathrm{~F} \$$ \\
\hline $\mathrm{n} / \mathrm{a}$ & $\mathrm{n} / \mathrm{a}$ & $\mathrm{n} / \mathrm{a}$ \\
\hline $13.6^{\dagger}$ & $11.1 \%$ & $33.3+$ \\
\hline $18.82 \ddagger$ & $5.74 \dagger$ & $33.81+$ \\
\hline 12.9 FMHN $\dagger$ & 4.7 FMHN $\dagger$ & 34.5 FMHN \\
\hline $17.4 \mathrm{MHN} \ddagger$ & $4.5 \mathrm{MHN} \dagger$ & $35.5 \mathrm{MHN}+$ \\
\hline $12.5 \dagger$ & $4.5 \dagger$ & $34.5+$ \\
\hline $21.77 \mathrm{MSU}+$ & $5.66 \mathrm{MSU \dagger}$ & 28.16 MSU\# \\
\hline
\end{tabular}




\begin{tabular}{|c|c|c|c|c|}
\hline (2009). & physical violence and burnout. & $19.97 \mathrm{CMH} \$$ & $5.87 \mathrm{CMH}^{\prime}$ & $26.33 \mathrm{CMH} \#$ \\
\hline $\begin{array}{l}\text { Langdon et al., } \\
\text { (2007) }\end{array}$ & $\begin{array}{l}67 \% \text { interviews demonstrated evidence of high expressed emotion. Overall 'low' levels of burnout; specifically moderate to low levels of EE, low levels } \\
\text { of Dp and high levels of PA. Similar use of coping skills and job satisfaction scores to that, have been reported for general nurses. }\end{array}$ & $16.63 \ddagger$ & $5.37 \dagger$ & $11.52 \#$ \\
\hline Lauvrud et al., (2009) & $\begin{array}{l}\text { 95.7\% met exposure criteria for PTSD, but PTSD symptom prevalence was low and no-one met the full PTSD criteria. Low job satisfaction scores but } \\
\text { conversely also low burnout scores. }\end{array}$ & - & - & - \\
\hline Long et al., (2006) & $\begin{array}{l}\text { After intervention there was significantly improved 'involvement' 'clarity,' and 'co-worker cohesion.' Significant decrease in EE, Dp and increase in } \\
\text { PA. Significantly increased job satisfaction. Significantly reduced patient levels of disturbed behaviour. }\end{array}$ & $3.25 * \dagger$ & $9.3 \$$ & $31 \#$ \\
\hline Nathan et al., (2007) & $\begin{array}{l}\text { After intervention, significantly increased levels of EE among staff on female inpatient ward. Smaller increase in burnout among staff on male inpatient } \\
\text { ward. }\end{array}$ & $\mathrm{n} / \mathrm{a}$ & $\mathrm{n} / \mathrm{a}$ & $\mathrm{n} / \mathrm{a}$ \\
\hline $\begin{array}{l}\text { Oddie and Ousley., } \\
\text { (2007). }\end{array}$ & $54 \%$ of staff reported high levels of EE. Study indicated stress and burnout were mainly due to organizational factors- not due to patient factors. & $23 \$$ & $7 \$$ & $35 \$$ \\
\hline Redhead et al (2011) & $\begin{array}{l}\text { After intervention, Qualified and Unqualified staff showed significant improvement in knowledge and attitudes. Significant decrease in Dp for qualified } \\
\text { staff. More PSI was used in patient care plans. }\end{array}$ & $\begin{array}{l}19.44 \mathrm{Q} \dagger \\
15.73 \mathrm{U} \dagger\end{array}$ & $\begin{array}{l}5.22 \mathrm{Q} \dagger \\
7.09 \mathrm{U} \ddagger\end{array}$ & $\begin{array}{l}32.44 \mathrm{Q} * \\
35.55 \mathrm{U} \$\end{array}$ \\
\hline $\begin{array}{l}\text { Reninghaus et al., } \\
\text { (2007) }\end{array}$ & $\begin{array}{l}\text { Social and managerial support shown to be protective factors. Physical assault significantly associated with psychological distress. Staff demonstrated } \\
\text { high levels of self esteem and low levels of stress. }\end{array}$ & - & - & - \\
\hline
\end{tabular}

Table 1. Study results reporting on MBI subscale scores and classified as high, moderate and low according to MBI Scoring Key (Maslach et al., 1996). For the EE subscale (score 0-54): Low $=0-16$, Moderate $=17-26$ and $\mathrm{High}=\geq 27$

For the Dp subscale (score 0-30): Low $=0-6$, Moderate $=7-12$ and $\mathrm{High}=\geq 13$

For the PA subscale (score 0-48): Low $=\geq 39$, Moderate $=32-38$ and High $=0-31$

†Low, $¥$ Moderate, \# High 


\begin{tabular}{|c|c|c|c|c|c|c|c|c|}
\hline & Study & Sample $(\mathrm{N})$ & $\begin{array}{l}\text { Study Sites (Number, Location, } \\
\text { Nature) }\end{array}$ & $\begin{array}{l}\text { Response } \\
\text { Rate/ } \\
\text { Participation } \\
(\%)\end{array}$ & $\begin{array}{l}\text { Intervention description and Number } \\
\text { (N) }\end{array}$ & $\begin{array}{l}\text { Control description and Number } \\
\text { (N) }\end{array}$ & Primary Outcome & $\begin{array}{l}\text { Validated Measures } \\
\text { used }\end{array}$ \\
\hline 10 & $\begin{array}{l}\text { Berry et al., } \\
\text { (2012) }\end{array}$ & 38 Forensic Mental Health Nurses & $\begin{array}{l}\text { Single; Manchester, U.K., Low } \\
\text { Secure Unit. }\end{array}$ & $\begin{array}{l}66 \% \\
34 \% \text { at follow } \\
\text { up. }\end{array}$ & $\begin{array}{l}\mathrm{N}=25 \\
\text { Before intervention ('Challenging } \\
\text { Behaviour' workshop). }\end{array}$ & $\begin{array}{l}\mathrm{N}=13 \\
\text { After intervention ('Challenging } \\
\text { Behaviour,' workshop). }\end{array}$ & $\begin{array}{l}\text { Occupational stress, Burnout, Ward } \\
\text { atmosphere, Staff-patient relationships }\end{array}$ & WAI, MBI, WAS \\
\hline 2 & $\begin{array}{l}\text { Blumenthal et } \\
\text { al., (2011) }\end{array}$ & 70 Forensic Mental Health Nurses & $\begin{array}{l}\text { Single; Liverpool, U.K.; High } \\
\text { Secure Unit }\end{array}$ & $51.4 \%$ & $\begin{array}{l}\mathrm{N}=18 \\
\text { Weekly multi-disciplinary reflective } \\
\text { practice. }\end{array}$ & $\begin{array}{l}\mathrm{N}=18 \\
\text { Parallel Staff Sample }\end{array}$ & $\begin{array}{l}\text { Occupational stress, Burnout, Ward } \\
\text { atmosphere, Staff-patient interaction }\end{array}$ & MBI, WAS \\
\hline 16 & $\begin{array}{l}\text { Chalder et al., } \\
(2000)\end{array}$ & $\begin{array}{l}60 \text { Forensic and Acute Mental Health } \\
\text { Nurses }\end{array}$ & $\begin{array}{l}\text { Multiple; West Midlands, U.K.; } \\
\text { Forensic and an Acute Mental Health } \\
\text { Unit. }\end{array}$ & $63 \%$ & $\begin{array}{l}\mathrm{N}=23 \\
\text { Forensic Mental Health nurses }\end{array}$ & $\begin{array}{l}\mathrm{N}=15 \\
\text { Acute Mental Health Nurses }\end{array}$ & Occupational stress & MHPSS \\
\hline 2 & $\begin{array}{l}\text { Coffey and } \\
\text { Coleman, } \\
(2001)\end{array}$ & $\begin{array}{l}104 \text { Forensic Community Mental Health } \\
\text { Nurses. }\end{array}$ & $\begin{array}{l}\text { Multiple; England \& Wales, U.K.; } \\
\text { Out-patient. }\end{array}$ & $77 \%$ & & - & Occupational stress, Burnout & MBI, GHQ, CPNSQ \\
\hline 23 & $\begin{array}{l}\text { Decaire et al., } \\
\text { (2006) }\end{array}$ & 25 Forensic Mental Health Nurses & $\begin{array}{l}\text { Single; Canada; Minimum Security } \\
\text { Unit }\end{array}$ & $52 \%$ & $+\infty$ & - & $\begin{array}{l}\text { Occupational stress, Burnout, Staff } \\
\text { personality traits in relation to violent } \\
\text { incidents. }\end{array}$ & NEO-FFI, WES, MBI \\
\hline 27 & $\begin{array}{l}\text { Dennis and } \\
\text { Leach, (2007) }\end{array}$ & $\begin{array}{l}30 \text { Staff: Health Care Workers and } \\
\text { Registered Nurses }\end{array}$ & $\begin{array}{l}\text { Single; England, U.K.; Medium } \\
\text { Secure Learning Disabilities Unit }\end{array}$ & $33 \%$ & 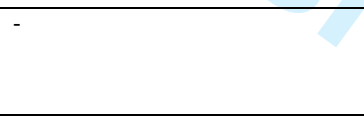 & & $\begin{array}{l}\text { Occupational stress, Burnout, Expressed } \\
\text { Emotion }\end{array}$ & FMSS, MBI \\
\hline 30 & $\begin{array}{l}\text { Ewers et al., } \\
\text { (2002) }\end{array}$ & 33 Forensic Mental Health Nurses & $\begin{array}{l}\text { Single; Merseyside, England, U.K.; } \\
\text { Medium Secure Unit }\end{array}$ & $60.6 \%$ & $\begin{array}{l}\mathrm{N}=10 \\
\text { Psychosocial Intervention Training } \\
\text { (PSI) }\end{array}$ & $\begin{array}{l}\mathrm{N}=10 \\
\text { Placed on waiting list for } \\
\text { intervention. }\end{array}$ & $\begin{array}{l}\text { Occupational stress, Burnout, Knowledge } \\
\text { and attitudes toward patients. }\end{array}$ & MBI \\
\hline 4 & $\begin{array}{l}\text { Happell et al., } \\
\text { (2003a) }\end{array}$ & $\begin{array}{l}191 \text { Forensic and General Mental Health } \\
\text { Nurses }\end{array}$ & $\begin{array}{l}\text { Single area; Melbourne, Australia; } \\
\text { Various }\end{array}$ & $67.5 \%$ & $\begin{array}{l}\mathrm{N}=51 \\
\text { Forensic Mental Health Nurses }\end{array}$ & $\begin{array}{l}\mathrm{N}=78 \text { General Mental Health } \\
\text { Nurses }\end{array}$ & $\begin{array}{l}\text { Occupational Stress, Burnout, Job } \\
\text { satisfaction }\end{array}$ & MBI, MJSS, SNCW \\
\hline & $\begin{array}{l}\text { Happell et al, } \\
\text { (2003b) }\end{array}$ & 95 Forensic Mental Health Nurses & $\begin{array}{l}\text { Single area; Melbourne, Australia; } \\
\text { Various }\end{array}$ & $54 \%$ & & & Occupational stress, Burnout & MBI, NSS \\
\hline
\end{tabular}




\begin{tabular}{|c|c|c|c|c|c|c|c|}
\hline $\begin{array}{l}\text { Howard et al., } \\
\text { (2009) }\end{array}$ & 190 Forensic Mental Health Staff & $\begin{array}{l}\text { Multiple; Birmingham, U.K.; } \\
\text { Community and Medium Secure } \\
\text { Inpatient settings. }\end{array}$ & $43.2 \%$ & $\begin{array}{l}\mathrm{N}=44 \\
\text { Staff in a medium secure unit (High } \\
\text { risk of violence). }\end{array}$ & $\begin{array}{l}\mathrm{N}=38 \\
\text { Staff working in the community } \\
\text { (Low risk of violence). }\end{array}$ & $\begin{array}{l}\text { Occupational stress, Burnout, Support, } \\
\text { Violent Incidents }\end{array}$ & $\begin{array}{l}\text { MBI, SSSQ(2), } \\
\text { Difficult Behaviour } \\
\text { Self-efficacy Scale. }\end{array}$ \\
\hline $\begin{array}{l}\text { Langdon et al., } \\
(2007)\end{array}$ & $\begin{array}{l}\text { Total Sample Number Not Available. } \\
27 \text { Mental Health Nurses Participated }\end{array}$ & $\begin{array}{l}\text { Single; Norwich, U.K.: Medium } \\
\text { Secure Unit for patients with } \\
\text { intellectual disabilities. }\end{array}$ & $\mathrm{N} / \mathrm{A}$ & - & - & $\begin{array}{l}\text { Occupational stress, Burnout, Expressed } \\
\text { Emotion, Coping Skills, Job satisfaction }\end{array}$ & $\begin{array}{l}\text { FMSS, MBI, Cooper } \\
\text { Coping Skills, GHQ- } \\
\text { 28, MJSS }\end{array}$ \\
\hline $\begin{array}{l}\text { Lauvrud et al., } \\
\text { (2009). }\end{array}$ & 100 Forensic Mental Health Nurses & Single; Norway; High Secure Unit & $70 \%$ & - & - & $\begin{array}{l}\text { PTSD symptoms, Occupational stress, } \\
\text { Burnout, Job satisfaction }\end{array}$ & PCL-C, Pro-QOL \\
\hline $\begin{array}{l}\text { Long et al., } \\
\text { (2006) }\end{array}$ & $\begin{array}{l}\text { Total Sample Number Not Available. } \\
12 \text { Mental Health Staff Participated }\end{array}$ & $\begin{array}{l}\text { Single; Northampton, England, U.K.; } \\
\text { Medium Secure Female } \\
\text { Developmental Disabilities Unit. }\end{array}$ & $\mathrm{N} / \mathrm{A}$ & $\begin{array}{l}\text { Sample prior to intervention (12 } \\
\text { week MDT individual and group } \\
\text { therapies). }\end{array}$ & $\begin{array}{l}\text { Sample six months after } \\
\text { intervention. }\end{array}$ & $\begin{array}{l}\text { Occupational stress, Burnout, Work } \\
\text { Environment, Job satisfaction. }\end{array}$ & WES, JDI, MBI, DBL \\
\hline $\begin{array}{l}\text { Nathan et al., } \\
(2007)\end{array}$ & $\begin{array}{l}47 \text { Forensic Mental Health Nurses. } \\
\text { (28 at Follow-up) }\end{array}$ & $\begin{array}{l}\text { Single; England, U.K.; Medium } \\
\text { Secure Unit }\end{array}$ & $\begin{array}{l}100 \% \\
59.6 \% \text { at } \\
\text { follow-up }\end{array}$ & $\begin{array}{l}\text { Staff on new female inpatient ward } \\
\text { (baseline and } 18 \text { month follow up). }\end{array}$ & $\begin{array}{l}\text { Staff on established male inpatient } \\
\text { ward (baseline and } 18 \text { month } \\
\text { follow up). }\end{array}$ & Occupational stress, Burnout & MBI \\
\hline $\begin{array}{l}\text { Oddie and } \\
\text { Ousley (2007) }\end{array}$ & $\begin{array}{l}115 \text { Forensic Mental Health Nurses } \\
9 \text { Occupational Therapists }\end{array}$ & $\begin{array}{l}\text { Single; England, U.K.; Medium } \\
\text { secure Unit }\end{array}$ & $57 \%$ & - & - & Occupational stress, Burnout & MBI, PNOSS \\
\hline $\begin{array}{l}\text { Redhead et al., } \\
\text { (2011) }\end{array}$ & $\begin{array}{l}79 \text { Forensic Mental Health Nurses: } \\
\text { Qualified (Q) and Unqualified (U). }\end{array}$ & $\begin{array}{l}\text { Single; Northwest England, U.K.; } \\
\text { Low security unit }\end{array}$ & $58 \%$ & $\begin{array}{l}\mathrm{N}=22(12 \mathrm{Q} 10 \mathrm{U}) \\
\text { Psychosocial Intervention Training } \\
\text { (PSI) }\end{array}$ & $\begin{array}{l}\mathrm{N}=20(9 \mathrm{Q} 11 \mathrm{U}) \\
\text { Placed on waiting list for } \\
\text { intervention. }\end{array}$ & $\begin{array}{l}\text { Occupational stress, Burnout, Knowledge } \\
\text { and attitudes toward patients. }\end{array}$ & $\begin{array}{l}\text { MBI, Attitude toward } \\
\text { PSI scale. }\end{array}$ \\
\hline $\begin{array}{l}\text { Reninghaus et } \\
\text { al., (2007) }\end{array}$ & $\begin{array}{l}\text { Sample Not Available. } \\
636 \text { Forensic Mental Health Nurses } \\
\text { Responded }\end{array}$ & Multiple; UK; High Secure Units & $22-28 \%$ & - & 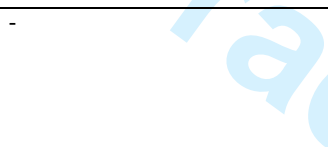 & $\begin{array}{l}\text { Occupational stress, Burnout, Self esteem, } \\
\text { Coping Mechanisms }\end{array}$ & $\begin{array}{l}\text { GHQ-12, Rosenberg } \\
\text { self esteem scale, PSS, } \\
\text { PNMCQ }\end{array}$ \\
\hline
\end{tabular}

Table 2. Description of studies measuring stress and burnout among forensic psychiatry mental health professionals. 
WES: Work environment scale; MBI: Maslach Burnout Inventory; JDI: Job Description Index; DBL: Disturbed Behaviour List; PSS: Perceived stress scale; PNMCQ: PsychNurse Methods of Coping Questionnaire; Rosenberg Self-Esteem Scale (modified version); GHQ: General Health Questionnaire (GHQ-12, GHQ-28 versions); Attitude to PSI scale; PCL-C: PTSD Checklist, civilian version; ProQOL: Professional Quality of Life Scale; JSS: Job Satisfaction Scale; SNCW: Satisfaction with Nursing Care and Work; NSS: The Nursing Stress Scale; WAS: Ward Atmosphere Scale; FMSS: Five Minute Speech; NEO-FFI: Neuroticism Extroversion Openness to Experience Five-Factor Inventory; WAI: Working Alliance Inventory; CPNSQr: Community Psychiatric Nurse Stress Questionnaire - revised; SSSQ version2: The Staff Support and Satisfaction Questionnaire - Version 2; Difficult Behaviour Self-efficacy Scale; CCSQ= The Cooper Coping Skills Questionnaire; MJSS= The Minnesota Job Satisfaction Scale; PNOSS= Psychiatric Nurse

Occupational Stress; MHPSS= Mental Health Professional Stress Scale. 